\title{
Citicoline for the Treatment of Head Injury: A Systematic Review and Meta-analysis of Controlled Clinical Trials
}

\section{Julio J Secades*}

Scientific Department. Ferrer, Barcelona, Spain

\begin{abstract}
Background: Citicoline is a neuroprotective/neurorestorative drug used in several countries for the treatment of traumatic brain injury (TBI). After the publication of the controversial COBRIT trial, the use of citicoline has been questioned in this use, so it has been considered necessary to undertake a systematicreview to evaluate if citicoline is effective in the treatment of patients with traumatic braininjury.

Methods: A systematic search was performed on Medline, Embase, and Ferrer databases to identify all published, unconfounded, comparative clinical trials of citicoline in acute phase head injured patients.

Results: 12 controlled trials enrolling 2706 patients were identified. Under the random-effects model, the metaanalysis shows an 1.815 (IC 95\% 1.302; 2.530) in favour of citicoline in the rates of independence, using as a measure the Glasgow Outcome Scale. The effect of citicoline has been diluted across time in parallel with the improvement of the standard of care of this kind of patient, as demonstrated by the cumulative meta-analysis technique.

Conclusion: Formal meta-analysis of comparative trials of citicoline in TBI shows a beneficial treatment effect, without safety concerns.
\end{abstract}

Keywords: Head injury; Neuroprotective therapies

\section{Introduction}

Traumatic Brain Injury (TBI) is an important worldwide health problem [1-4], being the first cause of mortality not related to cancer in young adults up to 40 years old [3] and, among the survivors of TBI, up to $43 \%$ have some kind of associated disability [1].

Among the main causes of TBI, we have traffic accidents, sports, falls, work-related accidents, aggressions, including gunshot wounds, blast injuries and other weapons. Thanks to the improvement in the development of devices to protect the occupants of vehicles and some other preventive measures, a reduction in the rate of mortality associated with TBI has been achieved [2,3], especially in the USA and Europe, but still there is a need to reduce the incidence of such injuries.

Furthermore, there is a need to reduce the severity for the morbidity associated with TBI and to improve the recovery of patients suffering this kind of injury. Treatment for TBI has improved evidently in the last years [5], improving the prognosis of these patients. Among the possibilities for a pharmacological approach to TBI, we have citicoline or CDP-choline, a neuroprotective / neurorestorative drug with a suitable profile of safety and efficacy for the treatment of the brain lesions associated with head trauma, ischemia and aging [6,7], although its role in the treatment of TBI has been questioned after the publication of the COBRIT trial [8], despite its being controversial study [9].

As citicoline is used in several countries for the treatment of TBI, it has been necessary to perform a systematic review of all the controlled clinical trials available, assessing the efficacy of citicoline in the treatment of TBI patients, to evaluate if there is enough evidence to support its use in this area. This is the objective of the review. As some studies were performed more than 30 years ago, a cumulative metaanalysis has been used to explore the hypothesis of a diluted effect of citicoline in parallel with the improvement of the standard of care of TBI patients.

\section{Materials and Methods}

A systematic search of the relevant terms was performed on
Medline, Embase, and Ferrer database (the company marketing the product in a number of countries) to identify all published, unconfounded, comparative clinical trials of citicoline in acute phase head injured patients. Studies were identified by searching electronic databases, scanning reference lists of articles, and consulting with experts in the field and at the pharmaceutical company (Ferrer).

To be included in the meta-analysis (Table 1), the trials must assess the effect of citicoline in the acute phase of TBI, be comparative studies and have independence outcomes, evaluated with the Glasgow Outcome Scale (GOS) or similar scales. All trials randomizing patients of any age or sex were included. No restrictions were applied in regard to doses, route of administration or duration of treatment. No restrictions regarding language, publication date or publication status was applied.

The primary efficacy measure was patient independence at the end of a scheduled follow-up period, evaluated as a score GOS 4-5, reflecting an excellent outcome or with mild sequelae, that guarantee an independence status after the TBI. In the trials where the GOS measure was not available, the most comprehensive measure of disability or handicap available from the trial was used.

The meta-analysis was performed using the software Meta Analyst version 3.13, developed by the Tufts Medical Center, member of the EPC group (Evidence-based Practice Centers). Results are presented as Odds Ratio (OR). As presumed, heterogeneity existed among the studies performed over 4 decades; so, the main analysis used the

*Corresponding author: Julio J Secades, Scientific Department. Ferrer, 08029, Barcelona, Spain, Tel: +34936003837; E-mail: jsecades@ferrer.com

Received November 12, 2014; Accepted December 15, 2014; Published December 17, 2014

Citation: Secades JJ (2014) Citicoline for the Treatment of Head Injury: A Systematic Review and Meta-analysis of Controlled Clinical Trials. J Trauma Treat 4: 227. doi:10.4172/2167-1222.1000227

Copyright: (c) 2014 Secades JJ. This is an open-access article distributed under the terms of the Creative Commons Attribution License, which permits unrestricted use, distribution, and reproduction in any medium, provided the original author and source are credited. 
random-effects model to determine if the effects of CDP-choline were statistically and significantly different from the control group. Also, the fixed-effects model was used as a sensitivity analysis to compare the estimates, because similar estimates could indicate that any small-study effects had little effect on the intervention effect estimate. The results of the meta-analysis are presented in Forest Plots, and the heterogeneity analysis is showed using a Funnel Plot.

\section{Results}

The systematic search detected 23 clinical trials, but only 12 were considered valid for the meta-analysis. The characteristics of these 12 studies selected and included in the meta-analysis are presented in Table 1. Among the clinical trials selected, there are six randomized and placebo-controlled studies [8,10-13], two randomized studies compared with another active therapy $[14,15]$, and another four studies comparing the effects of citicoline with a control group not receiving the active treatment [16-20].

Among the studies not selected for the meta-analysis there are four non-comparative studies [21-24], four studies not in the acute phase of TBI [25-28], and three randomized and controlled studies without independence data available [29-31].

The included studies involved 2706 patients with mild, moderate, or severe TBI treated in the acute phase with citicoline or not. The doses of citicoline ranged from $250 \mathrm{mg}$ to $6 \mathrm{~g}$ per day, administered orally or parenterally. The duration of the treatment ranged from 7 to 90 days.

According to the formal meta-analysis, based on randomeffect model (Figure 1), the use of citicoline is associated with a significant increase in the rates of independence with an OR of 1.815 $(95 \% \mathrm{CI}=1.302 ; 2.530)$, but a significant heterogeneity $\left(\mathrm{I}^{2}=54.6 \%\right.$; $\mathrm{p}=0.001$; Figure 2) was detected, reflecting the time gap of 34 years between the studies included in the meta-analysis. The funnel plot in Figure 2 shows evidence of asymmetry, and this asymmetry reflects the progressive improvement of the standard of care over time. The cumulative meta-analysis presented in Figure 3 shows how the effect of the intervention decreases over time in parallel with expected improvements in the standard of care.

The meta-analysis under the fixed-effects model (Figure 4) obtains an OR of $1.451(95 \% \mathrm{CI}=1.224 ; 1.721)$, reinforcing the results obtained.

\section{Discussion}

Citicoline is a drug marketed in more than 60 countries around the world and is used for the treatment in the acute phase of acute stroke and TBI, and for the treatment of the sequelae of these pathologies. The experimental data showed a pleiotropic effect of citicoline the underlying common molecular mechanisms [32] involved in the pathophysiology of the brain injury, both ischemic or traumatic [6].

In general, the treatment of TBI patients with citicoline has been associated with an improvement in the outcome and the quality of life of these patients, together with a reduction in the length of the hospital stay and the need for rehabilitation [6]. Citicoline also is considered a useful co-adjuvant therapy during the rehabilitation process [2628]. Nevertheless after the recent publication of the COBRIT trial [8], these results have been questioned. The COBRIT trial is the largest study performed with citicoline in this indication, but there are several methodological issues that question seriously the validity and applicability of the results obtained. The first point to consider is that this study was an independent study, financed by the US National Institute of Health, with a limited budget. A point to consider is the sample size calculation. The authors chose an OR of 1.4 as the effect of the treatment, when in the most recent publications; the size of the effect of citicoline has been 1.26 in acute ischemic stroke patients, a less heterogeneous pathology than TBI. It appears that the sample size was calculated based on the number of patients that could be afforded and then the OR of the treatment was established accordingly, rather than basing it on the effects of the drug. A more conservative and realistic OR of 1.2 or less would result in a sample size which was much higher but that would likely have been unaffordable for the authors. Another point to consider is that the authors mixed different populations, confusing mild, moderate and severe TBI. The pathophysiology, localization, and trajectory for recovery can be very different among these groups. One means of avoiding this would have been to use a randomized, matched sample design. This mixing of lesion severity is a clear source of heterogeneity and would have to be considered an important confounding factor in the analysis and interpretation of the data. Also the oro-enteral administration of citicoline used in this trial is completely atypical, is not approved in any country, has not previously been scientifically tested and additionally is not appropriate for many of the patients enrolled in the study. But the most controversial point is the poor compliance of the treatment. A compliance of only $44.4 \%$ of patients having taken more than $75 \%$ of the medication expected is very low and needs to be explained. Not receiving the active treatment is not the same as receiving the placebo, in terms of the standard of care being received. This means that less than half of the patients received something close to a therapeutic dose of citicoline. Thus, the COBRIT

\begin{tabular}{|c|c|c|c|c|c|}
\hline Study & Year & $\mathbf{n}$ & Severity & Control & Doses \\
\hline Misbach et al. [10] & 1978 & 80 & Moderate to severe & Placebo & $300 \mathrm{mg} \mathrm{IV} \times 14 \mathrm{~d}$ \\
\hline Espagno et al. [11] & 1979 & 46 & Severe & Placebo & $250 \mathrm{mg}$ IV or IM $\times 20 \mathrm{~d}$ \\
\hline Richer et al. [12] & 1980 & 60 & Severe & Placebo & $750 \mathrm{mg}$ IV or IM $\times 20 \mathrm{~d}$ \\
\hline Cohadon et al. [13] & 1982 & 60 & Severe & Placebo & $750 \mathrm{mg}$ IV or IM $\times 20 \mathrm{~d}$ \\
\hline Lecuire et al. [14] & 1982 & 25 & Moderate to severe & Meclophenoxate & $750 \mathrm{mg}$ IV $\times 10 \mathrm{~d}$ \\
\hline Lecuire [15] & 1985 & 40 & Moderate to severe & Piracetam & $750 \mathrm{mg} \mathrm{IV} \times 10 \mathrm{~d}$ \\
\hline Ogashiwa et al. [16] & 1985 & 101 & Severe & Control & $1000 \mathrm{mg} \mathrm{IV} \times 7 \mathrm{~d}$ \\
\hline Raggueneau et al. [17] & 1988 & 921 & Severe & Control & $500-750 \mathrm{mg} \mathrm{IV} \times 20 \mathrm{~d}$ \\
\hline Calatayud et al. [18] & 1991 & 216 & Moderate to severe & Control & $\begin{array}{l}3-4 \mathrm{~g} \mathrm{IV} \times 4 \mathrm{~d} \\
2 \mathrm{~g} \mathrm{p} .0 . \times 26 \mathrm{~d}\end{array}$ \\
\hline Lozano [19] & 1991 & 78 & Moderate to severe & Control & $3-6 \mathrm{~g} \mathrm{IV} \times 14 \mathrm{~d}$ \\
\hline Aniruddha et al. [20] & 2009 & 62 & Mild & Placebo & 1 g p.o. $\times 30 d$ \\
\hline Zafonte et al. [8] & 2012 & 1070 & $\begin{array}{c}\text { Mild complicated, moderate } \\
\text { \& severe }\end{array}$ & Placebo & $2 \mathrm{~g} \mathrm{p} .0 \times 90 \mathrm{~d}$ \\
\hline
\end{tabular}

Table 1: Characteristics of the trials included in the meta-analysis. 


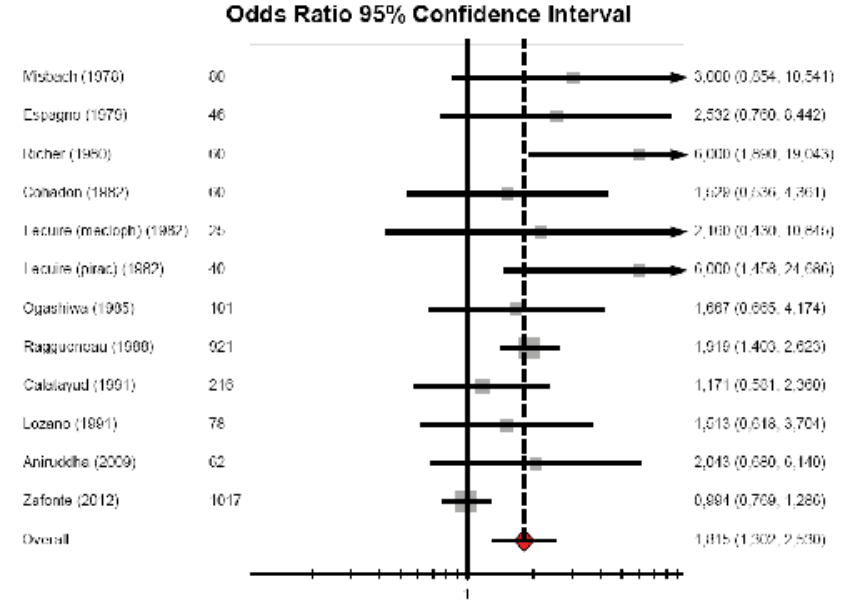

Figure 1: Forest Plot of the meta-analysis based on the random-effects model OR $1.815(95 \% \mathrm{Cl}=1.302 ; 2.530)$

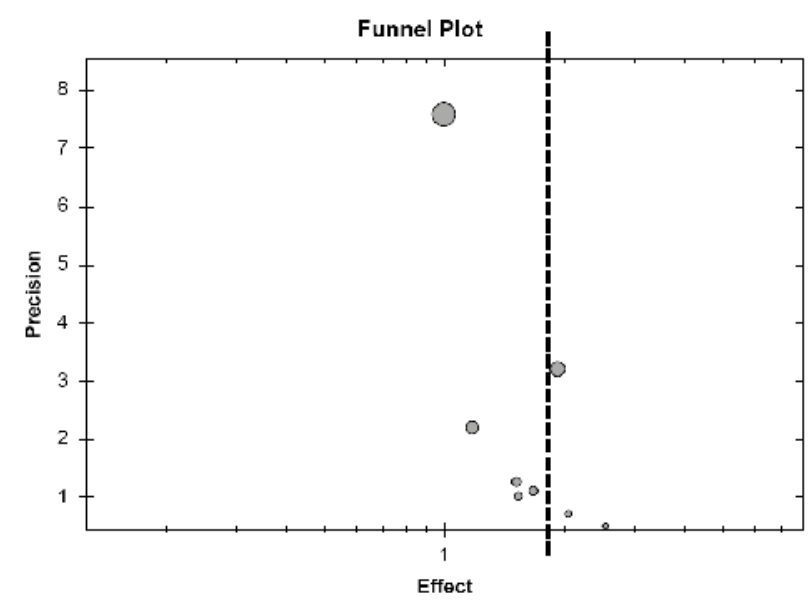

Figure 2: Funnel Plot showing the significant heterogeneity $\left(I^{2}=54.6 \%\right.$ $\mathrm{p}=0.001$ ) between the different studies.

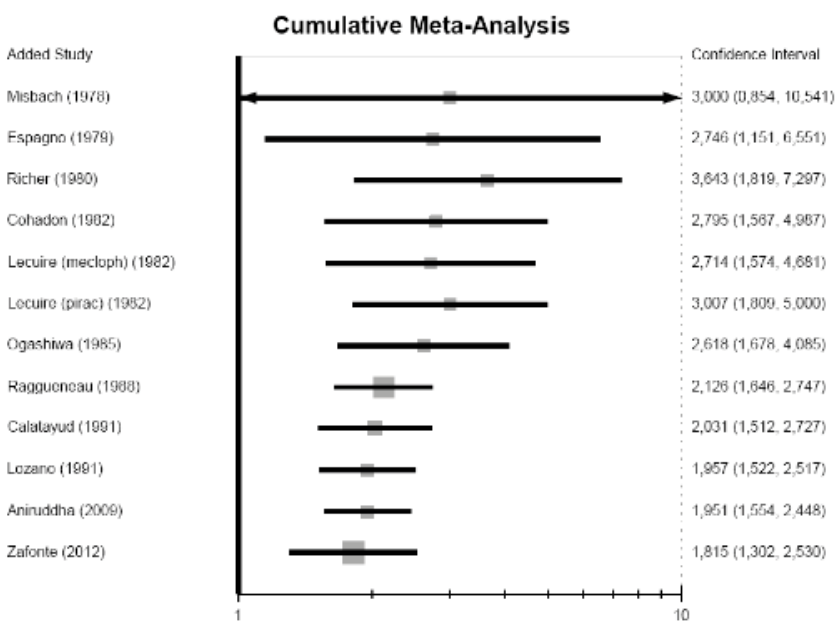

Figure 3: Forest Plot for the cumulative meta-analysis (random-effects model) OR $1.815(95 \% \mathrm{Cl}=1.302 ; 2.530)$.

\section{Odds Ratio $\mathbf{9 5} \%$ Confidence Interval}

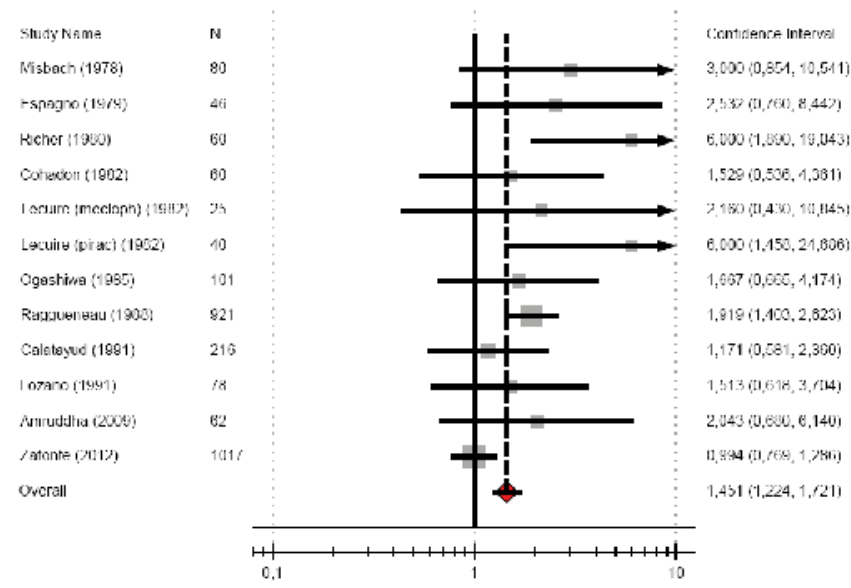

Figure 4: Forest Plot of the meta-analysis based on the fixed-effects model. OR $1.451(95 \% \mathrm{Cl}=1.224 ; 1.721)$.

trial is not the definitive study on citicoline, especially when the methodological confounds just described are taken into consideration.

Given the controversy after the publication of the COBRIT trial, it is interesting to assess if there is a real effect of citicoline on the recovery of patients with TBI. To perform this assessment the tools of Evidence Based Medicine (EBM) have been used. The performed meta-analysis of the comparative studies detected shows that citicoline could still play a role in the pharmacological approach to TBI in the countries where the drug is approved and marketed. However, as always, the results obtained from the EBM should be used as a guide or orientation on how to act in everyday practice, and, together with personal experience, try to improve the outcome obtained.

After the publication of the ICTUS trial [33] on acute ischemic stroke, it was hypothesized that the beneficial effect of citicoline over time was diluted in parallel with improved standards of care [33,34], and a similar behaviour has been shown in the present cumulative meta-analysis presented in this paper. Citicoline has an excellent safety profile, demonstrated not only in clinical trials, but also in day to day practice $[6,8,10-31,33]$.

With regards to the results obtained in this systematic review, we can conclude that there is enough evidence for the use of citicoline in the treatment of TBI patients, and, as a consequence, citicoline should be considered as a valid approach to treat such patients in the countries where the drug is available.

\section{References}

1. Corrigan JD, Selassie AW, Orman JA (2010) The epidemiology of traumatic brain injury. J Head Trauma Rehabil 25: 72-80.

2. Leibson CL, Brown AW, Ransom JE, Diehl NN, Perkins PK, et al. (2011) Incidence of traumatic brain injury across the full disease spectrum: a population-based medical record review study. Epidemiology 22: 836-844.

3. Coronado VG, Xu L, Basavaraju SV, McGuire LC, Wald MM, et al. (2011) Surveillance for traumatic brain injury-related deaths--United States, 19972007. MMWR Surveill Summ 60: 1-32.

4. Terrio H, Brenner LA, Ivins BJ, Cho JM, Helmick K, et al. (2009) Traumatic brain injury screening: preliminary findings in a US Army Brigade Combat Team. J Head Trauma Rehabil 24: 14-23.

5. Maas Al, Stocchetti N, Bullock R (2008) Moderate and severe traumatic brain injury in adults. Lancet Neurol 7: 728-741. 
Citation: Secades JJ (2014) Citicoline for the Treatment of Head Injury: A Systematic Review and Meta-analysis of Controlled Clinical Trials. J Trauma Treat 4: 227. doi:10.4172/2167-1222.1000227

Page 4 of 4

6. Secades JJ (2011) Citicoline: pharmacological and clinical review, 2010 update. Rev Neurol 52 Suppl 2: S1-1S62.

7. Adibhatla RM, Hatcher JF, Dempsey RJ (2002) Citicoline: neuroprotective mechanisms in cerebral ischemia. J Neurochem 80: 12-23.

8. Zafonte RD, Bagiella E, Ansel BM, Novack TA, Friedewald WT, et al. (2012) Effect of citicoline on functional and cognitive status among patients with traumatic brain injury: Citicoline Brain Injury Treatment Trial (COBRIT). JAMA 308: $1993-2000$

9. Adibhatla RM (2013) Citicoline in stroke and TBI clinical trials. Nat Rev Neurol 9: 173.

10. Misbach J, Andradi S, Harahap TP, Soemargo S, Markam S (1978) Doubleblind trial of Nicholin (CDP-choline) on the patients with severe head injury. Biannual Meeting of Neurology, Psychiatry and Neurosurgery, Surabaya (Indonesia).

11. Espagno J, Tremoulet M, Gigaud M, Espagno Ch (1979) Etude de l'action de la CDPcholine dans les troubles de la vigilance post-traumatique. La Vie Médicale 3: 195-196

12. Richer E, Cohadon F (1980) Therapeutic trial of a precursor phospholipids on the treatment of severe traumatic comas. International Symposium: Suffering and cerebral phospholipid precursors Paris. Paris.

13. Cohadon F, Richer E, Poletto B (1982) [A precursor of phospholipids in the treatment of severe traumatic comas]. Neurochirurgie 28: 287-290.

14. Lecuire J, Duplay J (1982) Double-blind trial of citicoline versus meclofenossato in patients with head injury. Giorn Ital Searches Clin Terapeut 3: 51-55.

15. Lecuire J (1985) Traumatismes craniens: Etude comparative PiracetamCDPcholine. C R Ther Pharmacol Clin 3: 3-7.

16. Ogashiwa M, Sano K, Manaka S, Kitamura K, Kagawa M (1985) Effectiveness of CDPcholine on disturbance of consciousness (DOC). Novel biochemical, pharmacological and clinical aspects of cytidinediphosphocholine. Elsevier Science Publ Co NY.

17. Raggueneau JL, Jarrige B (1988) National Survey result in serious head injuries: Analysis of 219 injuries treated with CDP-choline [ National inquiry on the outcome of severe head injuries : analysis of 921 Injured Patients Treated with CDP-choline ]. Agressologie. 29: 439-443

18. Calatayud Maldonado V, Calatayud Pérez JB, Aso Escario J (1991) Effects of CDP-choline on the recovery of patients with head injury. J Neurol Sci 103 Suppl: S15-18.

19. Lozano $R$ (1991) CDP-choline in the treatment of cranio-encephalic traumata. J Neurol Sci 103 Suppl: S43-47.

20. Aniruddha TJ, Pillai S, Devi BI, Sampath S, Chandramouli BA (2009) Role of citicoline in the management of mild head injury. Indian J Neurotrauma. 6: 49-52
21. Moriyama M, Tsukumo T, Nakagawa $Y$ (1967) Effects of CDP-choline on head trauma. Gendai No Rinsho, 1: 114-120.

22. Oka M, Oku N, Kujiraoka Y, Yoshida S, Higashiguchi H (1968) The effects of cytidine diphosphate choline (CDP-choline) on patients with head injury. Shinryo to Shinyaku. $3: 1101-1104$

23. Lecuire J, Duplay J (1982) Trial of citicoline in a sample of 154 head injuries Giorn Ital Searches Clin Terapeut. 3: 61-67

24. De Blas A, Martinez Cubells J, Hernando C (1986) Assessment of the effectiveness of citicoline in the treatment of traumatic brain injury. Med Clin 87: $41-44$

25. Levin HS (1991) Treatment of postconcussional symptoms with CDP-choline. J Neurol Sci 103 Suppl: S39-42.

26. Leon-Carrion J, Dominguez JM, Murillo F, Domínguez MR, Muñoz MA, et al (1999) Advances in the treatment of memory deficits after brain injury: the role of citicholine. 3rd World Congress on Brain Injury, Quebec, Canada, Junio.

27. Carrion JL, Dominguez-Roldán JM, Cabezas FM, Dominguez-Morales MR Munoz-Sánchez MA (1999) Normalization of memory-related cerebral blood flow in severe traumatic brain injury patients and improvements of memory induced by citicholine (CDP-choline): the role of a pro-cognitive drug. ICRAN'99, Taipei (Taiwan).

28. Leon-Carrion J, Dominguez-Roldan JM, Murillo-Cabezas F, del Rosario Dominguez-Morales M, Munoz-Sanchez MA (2000) The role of citicholine in neuropsychological training after traumatic brain injury. NeuroRehabilitation 14: $33-40$.

29. Carcassonne M, Letourneau J (1979) Double-blind study of Rexort in childhood neurotrauma . life Medical.12:1007.

30. Lazowski T, Kierul K, Bartnicki M, Mayzner-Zawadzka E, Toczylowska B, Ryba $M$, Lewandowski Z. Effects of citicoline treatment in patients with isolated head trauma: a randomized trial. Critical Care. 2003;7(Suppl 2):P078

31. El Reweny EM, Okasha A, Hafez A (2012) The neuroprotective effect of citicholine (CDP choline) in patients with traumatic brain injury, 25th ESICM Annual Congress, Lisbon, Portugal.

32. Leker RR, Shohami E (2002) Cerebral ischemia and trauma-different etiologies yet similar mechanisms: neuroprotective opportunities. Brain Res Brain Res Rev 39: 55-73.

33. Davalos A, Alvarez Sabin J, Castillo J, Diez Tejedor E, Ferro J (2012) For the International Citicoline Trial on Acute Stroke (ICTUS) trial investigators. Citicoline in the treatment of acute ischaemic stroke: an international, randomised, multicentre, placebo-controlled study (ICTUS trial). Lancet. 2012;380:349-57

34. Secades JJ, Delgadillo J, Oudovenko N (2013) Role of citicoline on the treatment of ischemic stroke: a formal and cumulative meta-analysis. 7th World Congress on Controversies in Neurology. Istanbul Turkey. 